\title{
BIOSSENSOR ENZIMÁTICO PARA DETECÇÃO DE FUNGICIDAS DITIOCARBAMATOS. ESTUDO CINÉTICO DA ENZIMA ALDEÍDO DESIDROGENASE E OTIMIZAÇÃO DO BIOSSENSOR
}

Roberval Soares Lima e Gilvanda Silva Nunes*

Departamento de Tecnologia Química, Centro de Ciências Exatas e Tecnologia, Universidade Federal do Maranhão, Av. Portugueses, s/n, 65080-040 São Luís - MA, Brasil

Thierry Noguer e Jean-Louis Marty

Centre de Phytopharmacie, Université de Perpignan, 52, Avenue Paul Alduy, 66860 Perpignan Cedex, France

Recebido em 13/7/05; aceito em 3/4/06; publicado na web em 11/8/06

\begin{abstract}
ENZYMATIC BIOSENSOR FOR THE DETECTION OF DITHIOCARBAMATE FUNGICIDES. KINETIC STUDY OF ALDEHYDE DEHYDROGENASE ENZYME AND BIOSENSOR OPTIMIZATION. Initially, all major factors that affect the rate of the AldH-catalyzed reaction (enzyme concentration, substrate concentration, temperature and $\mathrm{pH}$ ) were investigated. Optimal activity was observed between $\mathrm{pH}$ values of 7.5 and 9.5 in the temperature range of 25 to $50{ }^{\circ} \mathrm{C}$. Kinetic parameters, such as $\mathrm{K}_{\mathrm{m}}\left(2.92 \mu \mathrm{mol} \mathrm{L} \mathrm{L}^{-1}\right)$ and $\mathrm{V}_{\text {max }}\left(1.3310^{-2} \mu \mathrm{mol}\right.$ $\mathrm{min}^{-1}$ ) demonstrate a strong enzyme-substrate affinity. The sensors were based on screen-printed electrodes modified with the Meldola BlueReinecke salt (MBRS) combination. Operational conditions $\left(\mathrm{NAD}^{+}\right.$and substrate contents, enzyme loading and response time) were optimized. Also, two enzyme immobilization procedures were tested: entrapment in poly(vinyl alcohol) bearing styrylpyridinium groups (PVA-SbQ) and crosslinking with glutaraldehyde. Chronoamperometry was employed to observe the biosensor responses during enzymatic hydrolysis of propionaldehyde and also to construct inhibition curves with maneb and zineb fungicides. Best results were found with the following conditions: $\left[\mathrm{NAD}^{+}\right]=0.25 \mathrm{mmol} \mathrm{L}^{-1}$; [propionaldehyde] $=80 \mu \mathrm{mol} \mathrm{L}^{-1}$; enzyme loading $=0.8 \mathrm{U}$ per electrode; response time $=$ $10 \mathrm{~min}$, and inhibition time $=10 \mathrm{~min}$. Current intensities around $103 \pm 13 \mathrm{nA}$ with the sensors and good stability was obtained for both immobilization procedures. Detection limits, calculated using $10 \%$ inhibition were $31.5 \mu \mathrm{g} \mathrm{L}^{-1}$ and $35 \mu \mathrm{g} \mathrm{L}^{-1}$ for maneb and zineb, respectively. Results obtained with other MBRS-modified electrodes consisting of mono and bi-enzymic sensors were compared. The ability to catalyze NADH oxidation by MB was also highlighted.
\end{abstract}

Keywords: AldH-based biosensors; dithiocarbamate fungicides; enzymatic kinetic.

\section{INTRODUÇÃO}

A investigação dos pesticidas constitui um caso delicado. A necessidade de analisar resíduos de pesticidas depara-se com problemas analíticos complexos, devido à gama de substâncias existentes em classes distintas e que devem ser determinadas em diferentes tipos de matrizes, sejam elas ambientais ou de alimentos ${ }^{1}$.

Entre os agrotóxicos mais difundidos atualmente, encontram-se os fungicidas ditiocarbamatos (DTC's). Tais compostos formam a mais importante classe de pesticidas empregados no controle de diversas doenças fungais em sementes, frutos e vegetais. Embora a toxidade aguda dos DTC's seja relativamente baixa, existe uma urgente necessidade de se encontrar um método de detecção sensível, confiável, e que permita rápidas tomadas de decisão, no caso de intoxicação em trabalhadores rurais e/ou contaminação ambiental ou alimentar. Isto devido ao fato de que, dependendo dos compostos encontrados, estes podem vir a ser carcinogênicos ${ }^{2}$, goitrogênicos ${ }^{2}$, mutagênicos ${ }^{3-5}$, teratogênicos ${ }^{3,6,7}$, provocar distúrbios neurológicos ${ }^{8}$ e, também, afetar a biota aquática ${ }^{9}$. Há uma grande preocupação com relação a certos compostos como, por ex., os fungicidas maneb e ditane, que contêm manganês, precursor do parkinsonismo, devido à ação do metal no sistema nervoso central ${ }^{8,10}$. Anualmente, são aplicadas milhares de toneladas de fungicidas nas lavouras brasileiras, o que levou à inclusão desses agroquímicos na lista prioritária de compostos que estão sendo controlados pela Organização Mundial da Saúde ${ }^{10}$.

Desafortunadamente, os DTC's encontram-se entre os contaminantes orgânicos que apresentam maior dificuldade de serem

*e-mail: vandasn@terra.com.br analisados. São compostos pouco solúveis em água (solubilidade variando de 0,02 a $18 \mathrm{mg} \mathrm{L}^{-1}$ ) e insolúveis na maioria dos solventes orgânicos ${ }^{11}$. Essa característica peculiar torna a análise extremamente difícil, já que os procedimentos de extração até então testados fornecem valores de recuperações muito baixos, em geral inadequados para análise de águas ${ }^{1,12}$. A adição de agentes complexantes mostrouse essencial para o aumento da eficiência de extração desses e outros compostos organometálicos ${ }^{13,14}$, mas as perdas por degradação ainda tornam baixas as recuperações ${ }^{14}$. Não existe, por ex., nenhum método imunoquímico para detecção de fungicidas DTC's ${ }^{15}$, e o método oficial, cujo limite de detecção (LD) é muito elevado para monitoramentos ambientais $\left(0,4 \mathrm{mg} \mathrm{L}^{-1}\right)$, é baseado na análise espectrofotométrica do $\mathrm{CS}_{2}$, derivado da decomposição ácida ${ }^{16,17}$.

Métodos cromatográficos têm resultado, em geral, em recuperações pobres, porém são mais reprodutíveis ${ }^{18,19}$. Baseiam-se na cromatografia líquida de alta eficiência, com detectores por fluorescência ou espectrometria de massas ${ }^{19,20}$ ou na cromatografia a gás, com detectores fotométrico de chama e espectrométrico de massas ${ }^{19,21}$. Alguns estudos recentes ${ }^{17,22}$ têm mostrado a aplicabilidade de um método espectroscópico baseado em molibdato de sódio para análise de DTC's, porém com LD de $0,3 \mathrm{mg} \mathrm{L}^{-1}$, considerado ainda muito elevado para fins de controle ambiental. Kubo et $a l .{ }^{23}$ propuseram um método baseado na quimiluminescência em presença do sal sódico de luminol, e os LD's variaram de 0,1 a 2,0 $\mu \mathrm{g} \mathrm{L}^{-1}$, dependendo do composto. $\mathrm{O}$ método exigiu o detector específico para quimiluminescência, sendo este aparato dispendioso para laboratórios que não utilizam a técnica rotineiramente.

Entre os escassos métodos eletroquímicos até hoje descritos para detecção dessa classe de fungicidas, o mais recente é baseado na 
voltametria cíclica (LD de $0,1 \mathrm{mgL}^{-1}$ para o fungicida tiram, por ex.) proposto por Hernández-Olmos et al. ${ }^{24}$. Noguer e Marty ${ }^{25}$ desenvolveram um biossensor bienzimático, baseado na oxidação de diferentes aldeídos pela enzima aldeído desidrogenase (AldH), em presença do cofator $\beta$-nicotinamida adenina dinucleotídeo $\left(\mathrm{NAD}^{+}\right)$. O NADH formado nessa primeira etapa era, então, reoxidado pela enzima diaforase, em presença de $\mathrm{Fe}(\mathrm{CN})_{6}^{3-}$, e esse processo dava origem a uma corrente elétrica, que era monitorada durante a reação enzimática global. A enzima AldH foi imobilizada em uma membrana de celofane, na superfície de um eletrodo de Pt. O método, embora sensível $\left(\mathrm{LD}=1,5 \mu \mathrm{g} \mathrm{L}^{-1}\right)$, apresentou reprodutibilidade baixa, além de ser relativamente caro, uma vez que emprega duas enzimas.

Levando em conta que, na atualidade, os biossensores são consideradas poderosas ferramentas analíticas, pois fazem uso do bioreconhecimento, que resulta em respostas rápidas e sensíveis, combinando a seletividade das reações bioquímicas com a simplicidade operacional, resolvemos desenvolver um biossensor monoenzimático, explorando a atividade catalítica da enzima AldH. A enzima foi imobilizada em um eletrodo de grafite contendo, como mediador, "Meldola Blue" (MB) combinado com sal de Reinecke (RS). Embora o alvo biológico dos DTC's seja ainda desconhecido, tem sido demonstrado que esses fungicidas inibem fortemente a $\mathrm{AldH}^{25}$, que é dependente do $\mathrm{NAD}^{+25,26}$. No sistema aqui proposto, o NADH produzido na reação será reoxidado usando o MBRS como um aceptor de elétrons, presente em um eletrodo de grafite (Figura 1). Essa estratégia tem sido utilizada em vários processos que empregam enzimas $\mathrm{NAD}^{+}$-dependentes ${ }^{27-29}$. O princípio de detecção do biossensor será baseado na inibição irreversível da enzima AldH, inibição esta proporcional à concentração dos DTC's.

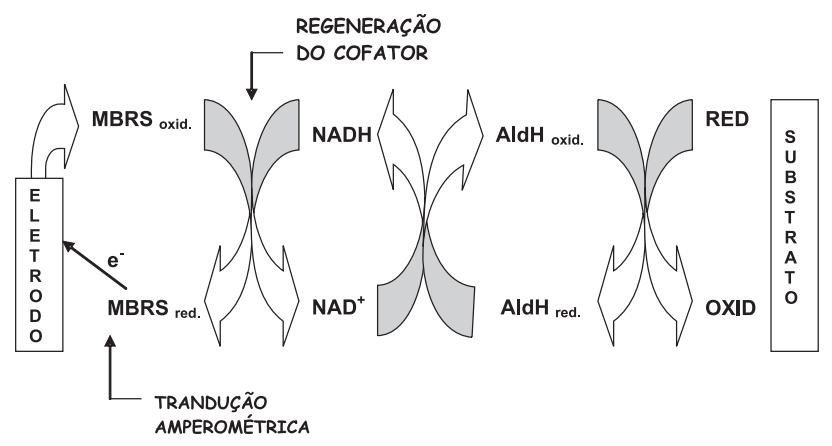

Figura 1. Princípio de funcionamento do biossensor NAD-dependente a base da enzima aldeído desidrogenase $(\mathrm{AldH})$. A reoxidação do $\mathrm{NADH}$ formado ocorre em presença do mediador eletroquímico Meldola's Blue combinado com sal de Reinecke (MBRS)

Inicialmente, foi realizado um estudo do comportamento cinético da $\mathrm{AldH}$, tendo sido otimizadas as condições operacionais para seu melhor desempenho. Depois, foram estudadas e padronizadas as condições para construção e uso do biossensor, tomando como ponto de partida a inibição provocada por dois DTC's amplamente utilizados na agricultura brasileira: maneb e zineb, de baixa solubilidade em água. Foram avaliados parâmetros como sensibilidade e estabilidade operacional do biossensor otimizado.

\section{PARTE EXPERIMENTAL}

\section{Reagentes, soluções e demais materiais}

A enzima aldeído desidrogenase (AldH), o substrato (propionaldeído) e o cofator $\beta$-nicotinamida adenina dinucleotídeo $\left(\mathrm{NAD}^{+}\right.$) foram obtidos de Sigma-Aldrich Co. (St. Louis, MO, EUA).
As soluções-estoque da enzima foram preparadas em concentrações de $3,5 \mathrm{mg} \mathrm{mL}^{-1}$; as soluções de trabalho foram obtidas da diluição destas em tampão fosfato, PBS ( $\mathrm{pH} 8,5)$ com concentrações variando de 0,5 a $3,0 \mathrm{mg} \mathrm{mL}^{-1}$ e distintas atividades relativas $^{25}$, expressas em $\mathrm{U} \mathrm{mL} \mathrm{m}^{-1}(\mathrm{U}=$ Unidade de Atividade, isto é, o número de $\mu$ mols de substrato hidrolisado por minuto de reação). A solução-tampão fosfato (PBS, $\mathrm{pH} 8,5$ ) foi preparada pela combinação de $\mathrm{Na}_{2} \mathrm{HPO}_{4}$ e $\mathrm{KCl} 0,1$ mol L${ }^{-1}$ (Merck, Steinheim, Alemanha). Hidroxietilcelulose (HEC) foi obtido de Fluka Chemie (Basel, Suíça). Alguns ensaios enzimáticos necessitaram da combinação de diferentes soluções-tampão como, por ex., tris-glicinato de sódio 0,1 mol L-1 (pH 9,5) e PBS contendo $\mathrm{H}_{3} \mathrm{PO}_{4}(\mathrm{pH} 3,0)$ (Merck, Steinheim, Alemanha). Os pesticidas maneb (95\% pureza) e zineb (94\% pureza) foram obtidos da Supelco (Bellefonte, USA); as soluções-estoque foram preparadas por dissolução em água deionizada (0,18 micro $\Omega$, sistema Direct-Q, Millipore, EUA), seguida de sonicação por $2 \mathrm{~h}$. A concentração final das soluções dos pesticidas encontra-se na ordem de $500 \mu \mathrm{g} \mathrm{L}^{-1}$.

Para construção dos sensores eletroquímicos serigrafados, as seguintes pastas foram utilizadas: de prata e de $\mathrm{Ag} / \mathrm{AgCl}$ (marcas 423SS e 6037SS, respectivamente, Electrodag PF-410, Acheson, Plymouth, Inglaterra) e pasta de grafite (Marca Timrex T15, Lonza, Basel, Suíça). O mediador eletroquímico foi composto da mistura de MB com sal de Reinecke (RS), ambos obtidos da Merck (Steinheim, Alemanha). O compósito foi preparado dissolvendo-se, separadamente, 0,5 mmols do $\mathrm{RS}$ em $40 \mathrm{~mL}$ de água deionizada e 0,5 mmols de MB em $40 \mathrm{~mL}$ de água destilada. Em seguida, as duas soluções foram misturadas, e o precipitado MBRS foi mantido em contato com a solução-mãe durante 2 dias para envelhecimento. Após filtração em funil de Bückner e repetidas lavagens com água deionizada, o precipitado foi seco em estufa por $12 \mathrm{~h}$ a $50^{\circ} \mathrm{C}^{25,27}$.

Para a etapa de imobilização enzimática, os seguintes reagentes foram empregados: álcool polivinílico contendo grupamentos estirilpiridínicos (PVA-SbQ, forma betaína), obtido da empresa Toyo Gosei Kogyo Co. (Chiba, Japão); solução de glutaraldeído a 25\% (Fluka Chemie, Basel, Suíça), e soroalbumina bovina (BSA), da Biochemical BDH Lim. (Poole, Inglaterra).

\section{Equipamentos e acessórios}

Foram utilizados os seguintes equipamentos: espectrofotômetro Diode-Array, Hewlett-Packard, modelo 8451 A (Palo Alto, EUA) e espectrofotômetro UV-Vis Beckman, modelo DU 520 (Beckman Intruments, Inc., Fullerton, Califórnia, EUA), com a aquisição dos dados de absorbância sendo efetuada em função de tempo. As medidas de absorbância foram registradas durante o período de 1 min, tendo sido utilizadas cubetas descartáveis de poliestireno óptico (Sigma-Aldrich Co., St. Louis, MO, EUA). Ensaios na ausência de enzima serviram como branco. Durante os ensaios enzimáticos, a temperatura foi controlada por meio de um banho termostatizado, com agitação.

Para preparo dos sensores eletroquímicos, foi utilizada a máquina a serigrafia DEK 248 (DEK Ltd, Weymouth, Inglaterra), seguindo as etapas de deposição previamente descritas ${ }^{30,31}$, lembrando que, neste caso, o modificador eletroquímico foi o MBRS (Figura 2). As medidas cronoamperométricas (CA) foram realizadas com um potenciostato clássico, Methrohm, modelo 641 VA (Methrohm AG Herisau, Suíça), acoplado a um registrador BD40 (Kipp \& Zonen, Delft, Holanda). Para determinação das atividades enzimáticas, foi utilizado o espectrofotômetro UV-Vis Beckman, modelo DU 520 (Beckman Intruments, Inc., Fullerton, Califórnia, EUA), seguindo o protocolo apresentado na Tabela 1, adaptado do método originalmente proposto ${ }^{41}$. 
Tabela 1. Algumas propriedades dos fungicidas ditiocarbamatos selecionados

\begin{tabular}{|c|c|c|c|c|}
\hline DTC & $\mathrm{N}^{\circ} \mathrm{CAS}$ & Nomenclatura & Solubilidade & Usos \\
\hline \multirow[t]{2}{*}{ Maneb } & $12427-38-2$ & $\begin{array}{l}\text { IUPAC: manganês etileno-bis } \\
\text { (ditiocarbamato) } \\
\text { (polimérico) }\end{array}$ & $\begin{array}{l}\text { Em água: } 0,02 \mathrm{mg} \mathrm{L}^{-1} \\
\text { (praticamenteinsolúvel) }\end{array}$ & $\begin{array}{l}\text { Controle de doenças fungais. } \\
\text { Aplicação foliar em hortaliças, } \\
\text { frutos e flores }\end{array}$ \\
\hline & & $\begin{array}{l}\text { CAS: }[[2-[(\text { ditiocarboxi)amino] } \\
\text { etil]carbamoditioato]] } \\
\text { (2-)-kS,kS']manganês }\end{array}$ & Em solventes orgânicos: insolúvel & \\
\hline \multirow[t]{2}{*}{ Zineb } & $12122-67-7$ & $\begin{array}{l}\text { IUPAC: zinco etileno-bis } \\
\text { (ditiocarbamato) } \\
\text { (polimérico) }\end{array}$ & $\begin{array}{l}\text { Em água: } 10 \mathrm{mg} \mathrm{L}^{-1} \\
\text { (praticamenteinsolúvel) }\end{array}$ & Idem \\
\hline & & $\begin{array}{l}\text { CAS: [[2-[(ditiocarboxi)amino] } \\
\text { etil]carbamoditioato]] } \\
\text { (2-)-kS,kS']zinco }\end{array}$ & Em solventes orgânicos: insolúvel & \\
\hline
\end{tabular}
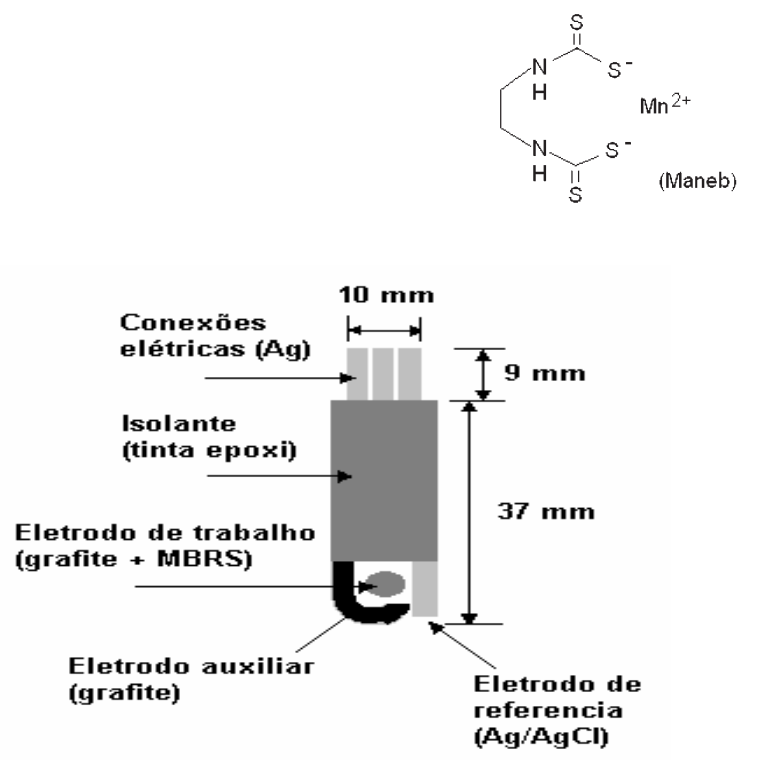

Figura 2. Biossensor serigrafado de três eletrodos. Na parte circular (eletrodo de trabalho), a mistura enzimática é manualmente depositada

\section{Cinética enzimática}

O método cinético utilizado baseia-se na reação de hidrólise do propionaldeído, catalisada pela enzima $\mathrm{AldH}$, em meio contendo a base $\mathrm{NAD}^{+}$. A reação dá origem ao ácido propiônico e o $\mathrm{NAD}^{+}$reduzido (NADH) (Figura 3). Nesse método, o ácido propiônico é medido<smiles>S=C([S-])NCCNC(=S)[Se-]</smiles>

indiretamente, através da medida de absorbância gerada em função do aparecimento do $\mathrm{NADH}^{25-27}$. Para verificar a velocidade de formação do NADH em função do tempo, foram fixadas, inicialmente, as concentrações do substrato, $\mathrm{S}$, e do $\mathrm{NAD}^{+}$, e variou-se o tempo de reação (Tabela 2). A temperatura de incubação dentro das células de reação foi mantida em $37^{\circ} \mathrm{C}$, e as leituras de absorbância, realizadas a $340 \mathrm{~nm}$, em um meio tamponado a $\mathrm{pH}$ 8,5. Foi efetuado um ensaiocontrole, contendo o substrato, mas em ausência de enzima.

A cinética enzimática foi estudada através da representação de Lineweaver-Burk, variando-se a concentração do substrato, [S], e verificando-se a resposta, em termos de absorbância, por um período de 15 min (Tabela 3). Após o tempo total de reação, esta foi interrompida através da adição de uma solução tampão contendo $\mathrm{H}_{3} \mathrm{PO}_{4}, \mathrm{pH} 3,0$.

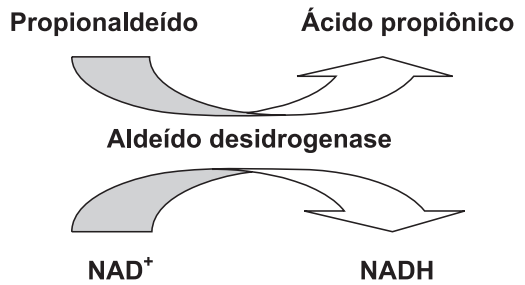

Figura 3. Reação de hidrólise do substrato, propionaldeído, em presença do $\mathrm{NAD}^{+}$, catalisada pela enzima aldeído desidrogenase (AldH)

Tabela 2. Esquema analítico para estudo cinético da reação de hidrólise do substrato (propionaldeído), catalisada pela enzima aldeído desidrogenase

\begin{tabular}{|c|c|c|c|c|c|c|c|}
\hline \multirow[t]{2}{*}{ Cubeta } & \multicolumn{4}{|c|}{ Volume $(\mu \mathrm{L})$} & \multicolumn{3}{|c|}{ Tempo $(\min )^{\mathrm{b}}$} \\
\hline & $\begin{array}{c}\text { Tampão fosfato } \\
\text { (pH 8,5) }\end{array}$ & $\begin{array}{c}\mathrm{NAD}^{+} \\
\left(10 \mathrm{mmol} \mathrm{L}^{-1}\right)\end{array}$ & $\begin{array}{c}\text { Solução da } \\
\text { enzima AldH a }\end{array}$ & $\begin{array}{c}\text { Substrato } \\
\text { (propional- } \\
\text { deído) }\end{array}$ & $\begin{array}{c}\text { Adição } \\
\text { da solução } \\
\text { da enzima }\end{array}$ & $\begin{array}{l}\text { Adição sol. } \\
\text { de interrupção } \\
\text { da reação }\end{array}$ & $\begin{array}{l}\text { Tempo total } \\
\text { de incubação }\end{array}$ \\
\hline 1 & 600 & 50 & 50 & 50 & 0,0 & 30,0 & 30 \\
\hline 2 & 600 & 50 & 50 & 50 & 0,5 & 25,5 & 25 \\
\hline 3 & 600 & 50 & 50 & 50 & 1,0 & 21,0 & 20 \\
\hline 4 & 600 & 50 & 50 & 50 & 1,5 & 16,5 & 15 \\
\hline 5 & 600 & 50 & 50 & 50 & 2,0 & 12,0 & 10 \\
\hline 6 & 600 & 50 & 50 & 50 & 2,5 & 7,5 & 5 \\
\hline 7 (controle) & 600 & 50 & - & 50 & - & 3,0 & 0 \\
\hline
\end{tabular}

${ }^{a}$ Preparada imediatamente antes do uso, contendo $2 \mathrm{U} \mathrm{mL}^{-1} ;{ }^{\mathrm{b}}$ tempo controlado por cronômetro; ${ }^{\mathrm{c}}$ após adição da solução da enzima, a solução resultante foi agitada vigorosamente em vortex; ${ }^{\mathrm{d}}$ soluçãotampão contendo ácido fosfórico, $\mathrm{pH}=3$ (vol. de adição: $200 \mu \mathrm{L}$ ). 
Tabela 3. Esquema analítico para determinação dos parâmetros cinéticos em função da concentração do substrato (propionaldeído)

\begin{tabular}{|c|c|c|c|c|c|c|c|c|c|}
\hline \multirow[t]{2}{*}{ Cubeta } & \multicolumn{6}{|c|}{ Volume $(\mu \mathrm{L})$} & \multicolumn{3}{|c|}{ Tempo (min) } \\
\hline & $\begin{array}{c}\text { ampão fosfato } \\
(\mathrm{pH} 8,5)\end{array}$ & $\begin{array}{c}\text { NAD } \\
\left(5 \mathrm{mmol} \mathrm{L}^{-1}\right.\end{array}$ & $\begin{array}{c}\text { Solução } \\
\text { )enzima AldH }\end{array}$ & $\begin{array}{c}\text { Água } \\
\text { destilada }\end{array}$ & $\begin{array}{c}\text { Substrato } \\
\text { (propionaldeído, } \\
7,5 \mu \mathrm{mol} \mathrm{L}{ }^{-1} \text { ) }\end{array}$ & $\begin{array}{c}\text { Substrato, } \\
\text { (propionaldeído } \\
15 \mu \mathrm{mol} \mathrm{L}{ }^{-1} \text { ) }\end{array}$ & $\begin{array}{c}\text { Adição } \\
\text { do substrato }\end{array}$ & $\begin{array}{l}\text { Adição sol. } \\
\text { interrupção }^{\text {b }}\end{array}$ & $\begin{array}{c}\text { Tempo total } \\
\text { do ensaio }\end{array}$ \\
\hline 1 & 600 & 50 & 50 & 30 & 20 & - & 0,0 & 15,0 & 15 \\
\hline 2 & 600 & 50 & 50 & 20 & 30 & - & 0,5 & 15,5 & 15 \\
\hline 3 & 600 & 50 & 50 & 10 & 40 & - & 1,5 & 16,5 & 15 \\
\hline 4 & 600 & 50 & 50 & 20 & - & 30 & 2,0 & 17,0 & 15 \\
\hline 5 & 600 & 50 & 50 & 10 & - & 40 & 3,0 & 18,0 & 15 \\
\hline 6 & 600 & 50 & 50 & - & - & 50 & 3,5 & 18,5 & 15 \\
\hline 7 (controle) & le) 600 & 50 & - & 50 & - & - & 4,0 & 19,0 & 15 \\
\hline
\end{tabular}

${ }^{a}$ Preparada imediatamente antes do uso $\left(2 \mathrm{U} \mathrm{mL}^{-1}\right)$; após adição da solução da enzima, a solução resultante foi agitada vigorosamente em vortex; ${ }^{\mathrm{b}}$ soluçãotampão contendo ácido fosfórico, $\mathrm{pH}=3$ (vol. de adição: $200 \mu \mathrm{L}$ ).

Foi também avaliado o efeito do $\mathrm{pH}$ e da temperatura sobre a atividade da enzima AldH. Para otimização da temperatura, o experimento esquematizado na Tabela 2 foi repetido, incubando-se a solução, após adição da enzima, em diferentes temperaturas. Para estudo do $\mathrm{pH}$, volumes diferentes das soluções tris ( $\mathrm{pH}$ 10,5) e glicina (pH 3,4) foram misturados (volume total de $600 \mu \mathrm{L}$ ), de modo a se obter soluções com valores de $\mathrm{pH}$ entre 4 e 10 . O tempo final do ensaio foi mantido em 15 min.

\section{Construção dos sensores serigrafados}

Sobre um suporte de PVC, foram depositadas, seqüencialmente, uma camada condutora de Ag ultrapura uma camada de grafite, uma camada da mistura $\mathrm{Ag} / \mathrm{AgCl}$, uma camada de grafite contendo o compósito MBRS misturado a uma solução de HEC a $3 \%(\mathrm{~m} / \mathrm{v})$ (proporção MBRS/grafite $=10: 90, \mathrm{~m} / \mathrm{m}$ ), e, finalmente, uma camada isolante de tinta epóxi. Trata-se, portanto, de um sensor com três conexões (canais), sendo que o eletrodo de referência foi depositado à direita, sobre a camada de grafite, e a parte circular central é o próprio eletrodo de trabalho, constituído da mistura grafite/MBRS/ HEC (Figura 2).

\section{Imobilização da enzima AIdH}

Foram testados dois procedimentos de imobilização da enzima AldH: 1) microencapsulamento em um gel de álcool polivinílico contendo grupamentos de estirilpiridina (PVA-SbQ) e, 2) ligação cruzada com glutaraldeído. Para o procedimento 1 , foi preparada uma pasta enzimática contendo 30\% (v/v) de PVA-SbQ e 70\% (v/v) da solução de AldH. A atividade enzimática, na solução utilizada para preparo da pasta, foi previamente determinada por espectrofotometria $^{25,32}$. Uma porção de $2 \mu \mathrm{L}$ dessa mistura foi depositada manualmente na superfície do eletrodo de trabalho. Em seguida, os biossensores permaneceram em repouso durante um período de, no mínimo, $4 \mathrm{~h}$ sob lâmpada de $\mathrm{Ne}$, à temperatura de $4{ }^{\circ} \mathrm{C}$. Após fotopolimerização, os eletrodos foram deixados em repouso em refrigerador por 2 dias antes do uso. O procedimento 2 foi baseado na reticulação da enzima em uma rede rígida, conforme metodologia previamente descrita por Nunes et al. ${ }^{31}$. Foi preparada uma pasta enzimática contendo 2,5\% (v/v) de glutaraldeído, 0,5\% (m/v) da proteína BSA e $97 \%$ (v/v) da solução da enzima AldH; em seguida, uma porção de $2 \mu \mathrm{L}$ da mistura foi depositada manualmente sobre o eletrodo de trabalho. Os biossensores permaneceram por cerca de 1 dia em câmara fria $\left(4{ }^{\circ} \mathrm{C}\right)$ antes do uso. Para ambos os procedimentos de imobilização, as atividades enzimáticas finais variaram de 0,125 a 0,8 U/eletrodo.

\section{Resposta do biossensor frente ao substrato e ao $\mathrm{NAD}^{+}$}

Durante as reações de hidrólise do substrato pela AldH, as respostas eletroquímicas foram quantificadas por cronoamperometria (CA), utilizando-se os biossensores contendo as enzimas imobilizadas em PVA-SbQ e em glutaraldeído. As medidas foram efetuadas, fixando-se um potencial de trabalho em $0 \mathrm{mV}$, contra o eletrodo de referência $\mathrm{Ag}$ / $\mathrm{AgCl}$, e registrando-se a corrente observada ao longo do tempo. $\mathrm{O}$ biossensor foi ligado ao potenciostato, mediante um conector de três canais apropriado e, em seguida, imerso em uma cubeta de vidro de 5 $\mathrm{mL}$ contendo a solução tampão. Após o registro da linha de base com o tampão, nova medida de corrente (I) foi registrada com o biossensor imerso na solução do substrato (propionaldeído $1,0 \mathrm{mmol} \mathrm{L}^{-1}$ ), em presença do cofator (solução de $\mathrm{NAD}^{+} 0,25 \mu \mathrm{mol} \mathrm{L}{ }^{-1}$ ). A fim de se obter uma corrente na ordem de 100 a $150 \mathrm{nA}$, foram otimizadas as seguintes condições operacionais: teores de $\mathrm{NAD}^{+}$e de $\mathrm{S}$ no meio reacional, quantidade de enzima por eletrodo e tempo de resposta.

\section{Ensaios de inibição da enzima AldH com os ditiocarbamatos}

Foram realizados ensaios de inibição, incubando-se os biossensores em soluções dos pesticidas maneb e zineb, durante um período de $10 \mathrm{~min}$, e tomando-se os valores de intensidades de corrente, antes (I ) e após inibição (I) ${ }^{30,31}$. A percentagem de inibição foi calculada usando soluções dos pesticidas com concentrações variando entre 50 a $300 \mu \mathrm{g} \mathrm{L} \mathrm{L}^{-1}$, utilizando-se a equação: $I R(\%)$ $=\left[1-\left(I / I_{o}\right)\right] \times 100$, onde $I R=$ inibição relativa; $I_{o}=$ intensidade de corrente antes da inibição enzimática; $I=$ intensidade de corrente após inibição enzimática. Curvas analíticas do tipo concentração do inibidor (em $\mu \mathrm{g} \mathrm{L}^{-1}$ ) versus $I R(\%)$ foram preparadas, tendo sido efetuados três ensaios para cada concentração do inibidor.

\section{Testes de precisão das medidas eletroquímicas}

Utilizando-se sensores construídos no mesmo dia e em dias diferentes, foram realizadas diversas medidas cronoamperométricas, a fim de verificar a reprodutibilidade, em termos de coeficiente de variação $(\mathrm{CV})$.

\section{RESULTADOS E DISCUSSÃO}

\section{Comportamento cinético da enzima AldH: efeito da concentração do substrato}

O principal objetivo da cinética enzimática é estudar a velocidade de reação e as condições que a afetam. A velocidade de uma 
reação catalisada por uma enzima é expressa como a alteração na concentração do substrato ou do produto, não só em função do tempo, mas também de outros parâmetros, tais como concentração da enzima, concentração do substrato, $\mathrm{pH}$ do ensaio, temperatura e concentração de ativadores e inibidores que podem estar presentes no meio reacional ${ }^{33}$.

O primeiro estudo de Michaelis e Menten já havia mostrado que a velocidade de reação tende a aumentar com a concentração do substrato $^{33}$. Mas, a elevadas concentrações de $\mathrm{S}$, a velocidade de reação permanece quase constante; este fato pôde ser comprovado nesse estudo, através da formação do produto de reação (NADH), em função do tempo, utilizando-se três diferentes concentrações do substrato: 5 , 7,5 e $10 \mathrm{mmol} \mathrm{L}^{-1}$ (Figura 4). Indubitavelmente, após várias tentativas para encontrar uma equação que representasse bem o fenômeno, Michaelis e Menten descobriram que seus dados poderiam ser plotados em uma equação hiperbólica ao quadrado. Diversos pesquisadores confirmaram a eficácia da equação de Michaelis-Menten (Equação 1) com diferentes enzimas.

$V_{o}=V_{\max }[S] / K_{m}+[S]$

onde: $\mathrm{V}_{\mathrm{o}}=$ velocidade inicial de reação; $\mathrm{V}_{\max }=$ velocidade de reação máxima teórica que pode ser encontrada com a máxima concentração do substrato; $[\mathrm{S}]$ = concentração do substrato; $\mathrm{K}_{\mathrm{m}}=$ constante de Michaelis-Menten.

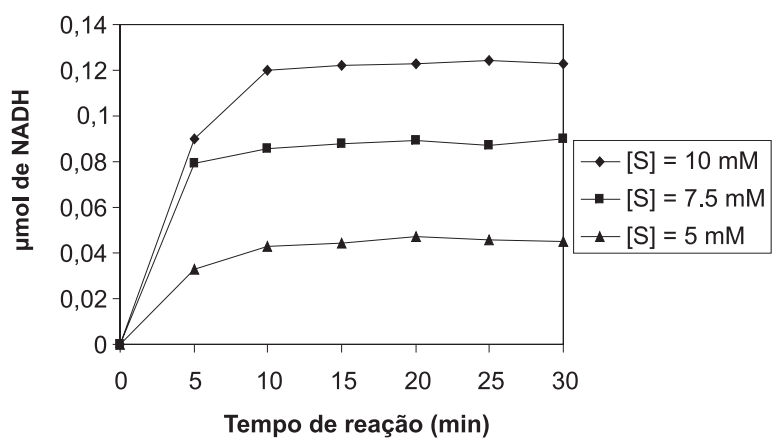

Figura 4. Formação do produto da reação $(N A D H)$ em função do tempo e da concentração do substrato, $S$. Condições operacionais: $\left[N A D^{+}\right]=0,67$ mmol $L^{-1} ;[$ AldH $]=0,133 \mathrm{U} \mathrm{mL}^{-1} ; \mathrm{pH}=8,5$ (tampão fosfato, contendo $\mathrm{KCl}$ $\left.0,1 \mathrm{~mol} \mathrm{~L}^{-1}\right) ; T=37^{\circ} \mathrm{C}$

Nesta equação, $[\mathrm{S}]=\mathrm{K}_{\mathrm{m}}$, quando $\mathrm{V}_{\mathrm{o}}=\mathrm{V}_{\max } / 2$. As duas constantes, $\mathrm{V}_{\max }$ e $\mathrm{K}_{\mathrm{m}}$ foram usadas nesse estudo para caracterizar a enzima AldH obtida comercialmente, que foi posteriormente utilizada no preparo dos biossensores seletivos para os fungicidas ditiocarbamatos. $\mathrm{V}_{\max }$ indica a rapidez com que a enzima usa o substrato, e $\mathrm{K}_{\mathrm{m}}$ mostra quanto do substrato é necessário para que a reação ocorra.

A Figura 4 fornece uma idéia da velocidade de formação do $\mathrm{NADH}$ - e, portanto, do ácido propiônico - em função do tempo. Observa-se que, logo nos primeiros 5 min de reação, a atividade enzimática foi bastante elevada, para todas as concentrações do substrato. Durante a reação empregando o teor mais elevado do substrato $\left(10 \mathrm{mmol} \mathrm{L}^{-1}\right)$, o produto formado acumulou-se dentro da célula de reação, atingindo um valor de absorbância próximo à unidade, em um tempo máximo de 10 min. A partir daí, a velocidade de reação manteve-se praticamente constante. Esse fenômeno de saturação com o substrato ocorre devido ao número limitado de sítios catalíticos ativos na enzima ${ }^{33}$. A valores baixos de [S], a velocidade de catálise foi ainda relativamente alta, e observou-se claramente uma região linear de valores de velocidade em função da [S]. Em valores de [S] mais elevados, a fase catalítica foi baixa, haven- do menos consumo de produtos com o passar do tempo. É a região de saturação catalítica.

Seguindo-se o esquema apresentado na Tabela 3, isto é, fixando-se o tempo de reação em 15 min e variando-se [S], os parâmetros cinéticos da reação enzimática $\left(\mathrm{V}_{\max }\right.$ e $\left.\mathrm{K}_{\mathrm{m}}\right)$ puderam ser determinados de acordo com a representação de Lineweaver-Burk, expressa na Equação 2

$1 / V_{o}=1 / V_{\max }+K_{m} / V_{\max } \times 1 /[S]$

Assim, um gráfico de $1 / \mathrm{V}_{\mathrm{o}}$ como função de $1 /[\mathrm{S}]$ fornecerá uma reta, onde o intercepto nas ordenadas é $1 / \mathrm{V}_{\max }$, e nas abscissas, $-1 / \mathrm{K}_{\mathrm{m}}$. Os dados cinéticos obtidos após ajuste da curva de regressão linear encontram-se na Tabela 4. A velocidade máxima foi expressa em uni-

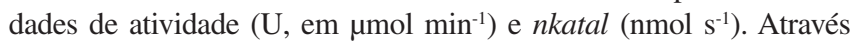

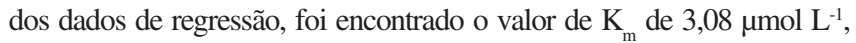
considerado relativamente baixo, o que indica uma grande afinidade da enzima pelo substrato selecionado, além de uma atividade enzimática adequada para construção de biossensores a partir das soluçõesestoque da AldH utilizada. Convém mencionar que os biossensores enzimáticos, em geral, utilizam enzimas imobilizadas, e o próprio procedimento de imobilização contribui para a diminuição da sua atividade catalítica; assim, é conveniente partir de uma combinação enzima/substrato que forneça, inicialmente, o máximo de atividade enzimática.

Tabela 4. Parâmetros cinéticos da reação de hidrólise do propionaldeído catalisada pela enzima aldeído desidrogenase

\begin{tabular}{lccccc}
\hline & \multicolumn{2}{c}{$\mathrm{V}_{\max }$} & & $-1 / \mathrm{K}_{\mathrm{m}}$ & $\mathrm{K}_{\mathrm{m}}$ \\
\hline $\begin{array}{l}\text { Parâmetros } \\
\text { cinéticos }\end{array}$ & $\mathrm{n}$ Katal & $\mathrm{IU}$ & $-0,325$ & 3,08 \\
\hline
\end{tabular}

\section{Efeito do pH e da temperatura sobre a atividade da AldH}

Os resultados apresentados na Figura 5 indicam que a atividade máxima da enzima AldH pode ser obtida em valores de $\mathrm{pH}$ entre 7,5 e 9,5. Essa característica da enzima concorda com os resultados apresentados por Oishi e Ebina ${ }^{35}$. Em todos os demais ensaios, um valor de $\mathrm{pH} 8,5$ foi mantido, mediante uso do tampão fosfato/ $\mathrm{KCl}$ $0,1 \mathrm{~mol} \mathrm{~L}^{-1}$. A presença do $\mathrm{KCl}$ no tampão deu-se também em função do ajuste da força iônica necessário às medidas com o biossensor enzimático, cujo eletrodo de referência é formado da combinação $\mathrm{Ag} / \mathrm{AgCl}$. Um determinado teor de cloreto no meio reacional é, pois,

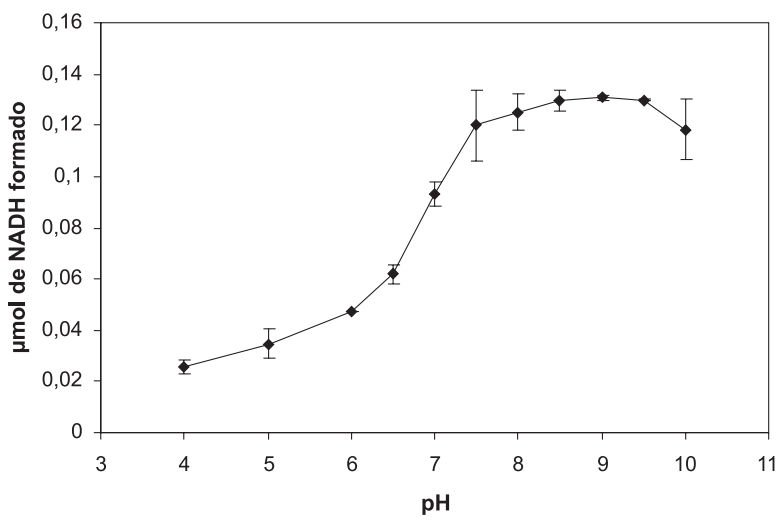

Figura 5. Efeito do $\mathrm{pH}$ sobre a atividade da enzima aldeído desidrogenase (AldH). Coeficientes de variação entre 1 e $15 \%(\mathrm{n}=3)$. Condições operacionais: $\left[N A D^{+}\right]=0,67 \mathrm{mmol} \mathrm{L}^{-1} ;[S]=0,67 \mathrm{mmol} \mathrm{L}^{-1} ;[$ AldH $]=0,133$ $U m L^{-1} ; T=37^{\circ} \mathrm{C}$ 
importante para manter a corrente estacionária relativamente baixa na linha de base, pois a presença do eletrólito suporte favorece a diminuição das correntes de migração e da resistência do meio.

Também foi observada maior quantidade de produto de reação, quando a solução do substrato foi incubada à temperatura de $50{ }^{\circ} \mathrm{C}$, em presença da enzima. Este resultado veio demonstrar a resistência da AldH à desnaturação, mesmo em valores mais elevados de temperatura. $\mathrm{O}$ ensaio pode ser também conduzido à temperatura ambiente controlada $\left(\sim 25{ }^{\circ} \mathrm{C}\right)$, com uma perda máxima de $6 \%$ na atividade da enzima livre, após 5 h de trabalho, aproximadamente.

\section{Resposta eletroquímica dos biossensores}

Através da voltametria cíclica, comprovou-se que o potencial de trabalho de $0 \mathrm{mV}$ versus $\mathrm{Ag} / \mathrm{AgCl}$ foi o que melhor se adequou ao processo enzimático em questão. Esse valor de potencial concorda com outros estudos ${ }^{24,27}$, tendo sido fixado para os demais experimentos. A estratégia de incorporação do MBRS mostrou-se bastante eficiente para a confecção dos eletrodos, uma vez que, nessa forma, foram evitadas perdas provocadas por desprendimentos da camada do mediador, provavelmente em virtude da diminuição da solubilidade do $\mathrm{MB}$, o que ocasionou maior estabilidade de resposta. Vasilescu et al..$^{27}$, baseados em estudos anteriores ${ }^{36,37}$, cujo objetivo era a utilização do MB como modificador eletroquímico para sensores $\mathrm{NAD}^{+}$-dependentes, investigaram diversas formas de incorporação desse mediador em eletrodos serigrafados, seja adicionando diretamente o composto ao grafite, seja realizando sua polimerização eletroquímica, ou mesmo produzindo o MBRS antes da incorporação ao eletrodo de grafite. Os autores encontraram melhores respostas quando utilizaram o MB não-combinado, porém a proporção MBRS/grafite testada foi de 2:98 (m/m). No presente estudo, o teor total do compósito MBRS na mistura com grafite foi aumentado para $10 \%(\mathrm{~m} / \mathrm{m})$, o que possivelmente favoreceu a diminuição das irregularidades observadas por Vasilescu et al. ${ }^{27}$, atribuídas a orifícios microscópicos, que tornavam mais áspera a superfície do eletrodo de trabalho e ocasionavam desprendimentos da camada enzimática. A maior relação MBRS/grafite proposta neste trabalho aumentou a estabilidade do sensor, independentemente do procedimento de imobilização empregado. Esses resultados concordam com as observações de Prieto-Simón e Fàbregas ${ }^{29}$, porém os autores relataram cerca de $37 \%$ de perda na sensibilidade do sensor preparado com MBRS, quando comparado àquele com o mediador MB puro. No presente estudo, para se obter ganho na reprodutibilidade das medidas do sensor, optou-se por perder em termos de sensibilidade.

\section{Otimização dos teores do $\mathrm{NAD}^{+}$, do substrato e da enzima AldH}

As concentrações do $\mathrm{NAD}^{+}$e do substrato tiveram que ser otimizadas, de modo a que se obtivesse uma intensidade de corrente inicial (antes da inibição) de 100 a 150 nA. Para verificar a resposta do sensor em função da concentração do substrato, fixou-se a concentração de $\mathrm{NAD}^{+}$em $0,25 \mathrm{mmol} \mathrm{L}^{-1}$ e variou-se a concentração de $\mathrm{S}$ de 10 a $120 \mu \mathrm{mol} \mathrm{L}{ }^{-1}$ (Figura 6). A concentração de $\mathrm{S}$ de 80 $\mu \mathrm{mol} \mathrm{L} \mathrm{L}^{-1}$ resultou em uma corrente de $105 \pm 15 \mathrm{nA}(n=3)$, sendo então escolhida para ensaios posteriores. Foi observada uma baixa dispersão dos dados em torno das médias de corrente (I).

A fim de se otimizar o teor da enzima AldH imobilizada no eletrodo de trabalho, variou-se a quantidade relativa de enzima de 0,125 a 0,8 U/eletrodo, mantendo-se as concentrações do $\mathrm{NAD}^{+} \mathrm{e}$ do propionaldeído em $0,25 \mathrm{mmol} \mathrm{L}^{-1}$ e $80 \mu \mathrm{mol} \mathrm{L}{ }^{-1}$, respectivamente. Os melhores resultados foram encontrados com a maior carga enzimática (0,8 U/eletrodo): intensidades de corrente de $108 \pm 6$

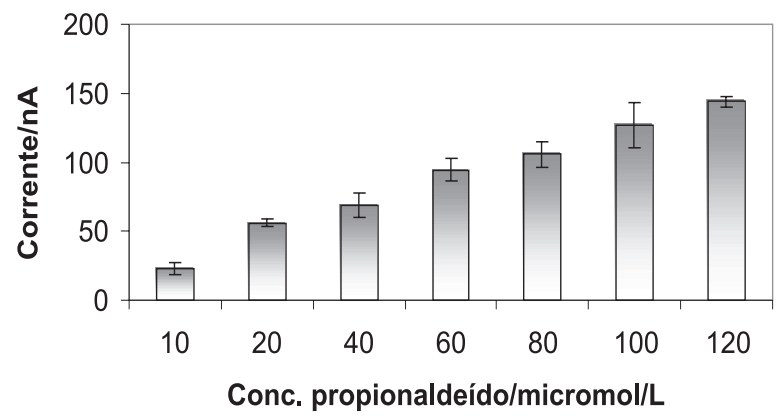

Figura 6. Efeito da concentração do substrato sobre a resposta do biossensor. Coeficientes de variação entre 3,5 e 8,6\% $(\mathrm{n}=3)$. Condições operacionais: Imobilização por fotopolimerização com PVA-SbQ; $[S]=80 \mu \mathrm{mol} \mathrm{L} \mathrm{L}^{-1} ;\left[\mathrm{NAD}^{+}\right]$ $=0,25 \mathrm{mmol} \mathrm{L}^{-1}$; potencial de trabalho $=0 \mathrm{mV}$ versus $\mathrm{Ag} / \mathrm{AgCl}$; tampão fosfato/ $\mathrm{KCl} \mathrm{0,1} \mathrm{mol} \mathrm{L}^{-1} ; \mathrm{pH} \mathrm{8,5;} \mathrm{T}=25^{\circ} \mathrm{C}$

nA e $94 \pm 2,0$ nA $(n=5)$, nos procedimentos de imobilização com PVA-SbQ e glutaraldeído, respectivamente (Figura 7). Esses valores de corrente foram considerados adequados para os ensaios posteriores, envolvendo a inibição da AldH pelos fungicidas selecionados. Noguer e Marty ${ }^{25}$ utilizaram uma quantidade cerca de 10 vezes menor da AldH, porém em um sistema bienzimático, onde o NADH produzido era depois reoxidado pelo $\mathrm{Fe}(\mathrm{CN})_{6}{ }^{3-}$ em presença da enzima diaforase. Os autores empregaram um eletrodo de $\mathrm{Pt}$ como eletrodo de trabalho, contendo a enzima imobilizada em celofane. Apesar da elevada sensibilidade ( $\mathrm{LD}=1,5 \mu \mathrm{g} \mathrm{L}^{-1}$ ), o sensor apresentou reprodutibilidade bastante baixa. Posteriormente, diferentes sensores e técnicas de imobilização foram testados, com o objetivo de melhorar a estabilidade desses tipos de sensores, porém baseados em sistemas unienzimáticos ${ }^{27-29,36,37}$.

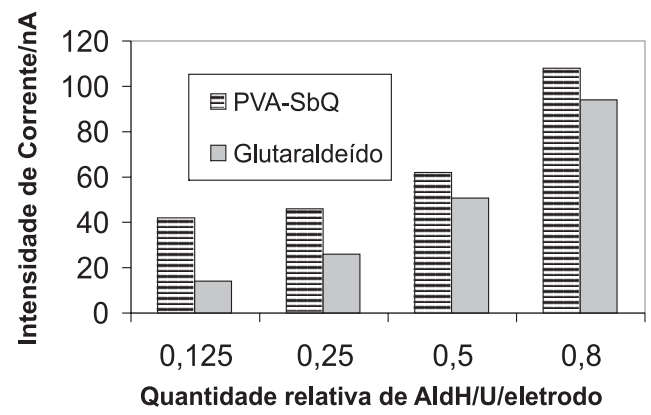

Figura 7. Comparação entre as respostas cronoamperométricas dos biossensores obtidos pelas duas técnicas de imobilização: reação cruzada com glutaraldeído e fotopolimerização com $P V A-S b Q)$. Condições operacionais: $[S]=80 \mu \mathrm{mol} \mathrm{L} L^{-1} ;\left[N A D^{+}\right]=0,25 \mathrm{mmol} \mathrm{L} L^{-1}$; potencial de trabalho $=0 \mathrm{mV}$ versus $\mathrm{Ag} / \mathrm{AgCl}$; tampão fosfato/ $\mathrm{KCl} \mathrm{0,1} \mathrm{mol} \mathrm{L}^{-1} ; \mathrm{pH} \mathrm{8,5;} \mathrm{T}$ $=25^{\circ} \mathrm{C}$

\section{Comparação entre as duas técnicas de imobilização}

A partir da otimização dos teores do $\mathrm{NAD}^{+}$e do substrato, do $\mathrm{pH}$ e da temperatura do meio, os dois processos de imobilização foram comparados, a partir das respostas cronoamperométricas dos respectivos biossensores (Figura 7). Em todas as concentrações da $\mathrm{AldH}$, foram obtidas respostas mais baixas para os sensores preparados com a enzima fixada com glutaraldeído, o que vem comprovar, efetivamente, que o glutaraldeído desnatura parcialmente a enzima. Tal fato foi observado anteriormente por Nunes et al. ${ }^{38}$, utilizando a enzima acetilcolinesterase (AChE). O método de fixação da enzima por fotopolimerização com PVA-SbQ (forma betaína) 
não apresentou tal inconveniente, porém a estabilidade operacional dos eletrodos foi um pouco menor; os valores de CV's para medidas obtidas com o mesmo sensor foram de 8,8 e 3,2\%, para imobilizações com PVA-SbQ e glutaraldeído, respectivamente. A maior variação entre as medidas, para o caso do PVA-SbQ, talvez se deva ao desprendimento de pequenas quantidades da fina camada enzimática durante as medidas. É conveniente, portanto, testar outras formas de PVA-SbQ, com o objetivo de estudar, em nível microscópico, o efeito da estrutura polimérica da camada biossensível. A fixação da enzima em retículo de glutaraldeído parece, até o momento, ser mais adequada para esse tipo de biossensor, apesar da inativação parcial da enzima, em função da maior simplicidade do procedimento. No presente trabalho, a reticulação foi realizada em presença da proteína inerte BSA, de modo a permitir melhor fixação da enzima no eletrodo de grafite ${ }^{38}$.

\section{Sensibilidade do biossensor: curvas de inibição}

Os ensaios de inibição foram executados como segue: o biossensor foi mergulhado em uma solução tamponada $(\mathrm{pH} 8,5)$, contendo o substrato e o cofator, sob agitação constante. A corrente gerada foi registrada após estabilização e, em seguida, o sensor foi cuidadosamente lavado com PBS pH 8,5. Seguiu-se, então, a incubação do biossensor em soluções diluídas dos fungicidas durante um período de $10 \mathrm{~min}$, sob agitação e com o potenciostato desligado. Esse tempo tem fornecido valores máximos de inibição para cada concentração do inibidor ${ }^{38}$. Após cada período de inibição, o biossensor e a célula eletroquímica foram lavados três vezes com PBS, e uma nova medida de corrente foi tomada, frente ao substrato. Os dados de inibição relativa (IR) foram plotados em um gráfico, em função da concentração do pesticida (Figura 8). A inibição da AldH, por ser irreversível, não permitiu a regeneração parcial dos sítios ativos da enzima, com a lavagem do sensor com PBS, o que normalmente acontece com os sensores à base de enzimas $\mathrm{AChE}$, cuja inibição com inseticidas carbamatos é reversível ${ }^{31,38}$. A irreversibilidade da inibição da AldH dá-se pela forte ação competitiva dos DTC's, o que explica a correlação linear entre a concentração do inibidor e a inibição relativa, mostrada na Figura 8. Do ponto de vista analítico, isso pode ser uma grande vantagem, pois um mesmo sensor poderá ser utilizado, com confiabilidade, várias vezes, desde que haja suficiente atividade enzimática, de modo que a diminuição da corrente provocada pela incubação do sensor com o inibidor não seja confundida com o ruído do equipamento de detecção. Aqui, foi observado que um mesmo sensor pode ser utilizado cerca de 4 a 5 vezes, desde que as concentrações dos inibidores esteja abaixo de $200 \mu \mathrm{g} \mathrm{L}^{-1}$ (IR entre 70 e $80 \%$ ). As faixas lineares de trabalho observadas na Figura 8 estão entre 50 e $250 \mu \mathrm{g} \mathrm{L}^{-1}$ para maneb, e entre 50 e $200 \mu \mathrm{g} \mathrm{L}^{-1}$ para zineb. Os LD's, calculados com base em um valor mínimo de $10 \%$ de IR, foram de 31,5 e de $35 \mu \mathrm{g} \mathrm{L}^{-1}$, para maneb e zineb, respectivamente. Esses valores demonstram uma sensibilidade adequada para análise desses compostos diretamente em amostras vegetais, pois estão dentro de uma faixa abaixo dos limites máximos recomendados (LMR's) pela Legislação Brasileira ${ }^{39}$, situados entre 0,3 e $0,5 \mathrm{mg} \mathrm{kg}^{-1}$. Segundo o que estabelece a legislação do $\mathrm{CONAMA}^{40}$, ainda não foram estipulados valores de referência para corpos de água, relacionados aos DTC's. Contudo, fazendo-se uma comparação com os padrões internacionais, os LD's aqui encontrados estão acima do que estabelece a legislação $\left(0,1 \mu \mathrm{g} \mathrm{\textrm {L } ^ { - 1 }}\right.$ para pesticidas individuais e seus produtos de degradação, e $0,5 \mu \mathrm{g} \mathrm{L}^{-1}$ para pesticidas totais) $)^{12}$. Por outro lado, encontram-se abaixo dos LD's encontrados para a maioria dos métodos hoje desenvolvidos para análise de DTC's, com a vantagem adicional de não haver necessidade de nenhum tipo de preparo da amostra, a não ser a filtra- (a)

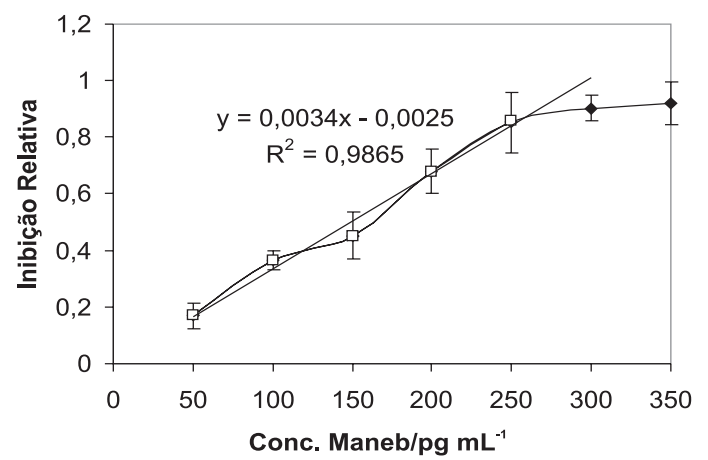

(b)

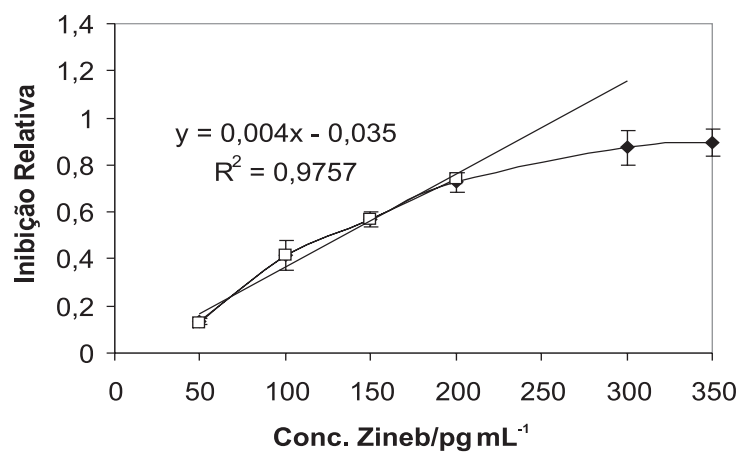

Figura 8. Curvas de inibição para os fungicidas maneb (a) e zineb (b). Incubação dos biossensores em concentrações do inibidor variando de 50 a $300 \mu \mathrm{g} L^{-1}(n=3)$. Condições operacionais: [propionaldeído] $=80 \mu \mathrm{mol} \mathrm{L} L^{-1}$; $\left[N A D^{+}\right]=0,25 \mathrm{mmol} \mathrm{L}^{-1}$; carga enzimática $=0,8$ U/eletrodo; tampão fosfato/ $\mathrm{KCl}$ 0,1 mol $\mathrm{L}^{-1}$ (pH 8,5); tempo de incubação do biossensor na solução do pesticida $=10 \mathrm{~min}$; potencial de trabalho $=0 \mathrm{mV}$ versus $\mathrm{Ag} / \mathrm{AgCl}$. Em destaque, a faixa linear (região de trabalho) de cada curva

ção prévia. Novos testes envolvendo a imobilização de menores quantidades de enzima e outros procedimentos de fixação poderão ser testados, de forma a aumentar a sensibilidade dos biossensores.

\section{Avaliação da estabilidade operacional do biossensor}

Foi avaliada a repetibilidade do sinal eletroquímico, obtido pelo mesmo sensor e por sensores diferentes, durante a reação enzimática. Ambos os procedimentos de imobilização da enzima forneceram valores adequados de $\mathrm{CV}$, com menores dispersões encontradas no método do glutaraldeído (medidas efetuadas com o mesmo sensor). Os resultados de estabilidade, baseados nos coeficientes de variação $(\mathrm{CV})$ podem ser assim resumidos: para imobilização com PVASbQ: CV de 6,2\% $(n=5)$ para ensaios com sensores diferentes, e confeccionados no mesmo dia, e CV de $8,8 \%$ para ensaios com o mesmo sensor $(n=4)$. $\mathrm{O}$ valor um pouco maior de $\mathrm{CV}$ em medidas efetuadas com o mesmo sensor provavelmente esteja relacionado com pequenas perdas da camada enzimática, durante as medidas eletroquímicas, que se processam sob agitação e, para a imobilização com glutaraldeído: CV de 7,4\% $(n=4)$ para ensaios com sensores diferentes, e confeccionados em dias diferentes; $\mathrm{CV}$ de $5,8 \%$ para ensaios com sensores diferentes, mas confeccionados no mesmo dia, e CV de 3,2\% para ensaios com o mesmo sensor $(n=6)$.

Os biossensores aqui construídos, por possuírem em sua camada sensível enzimas NAD-dependentes, reconhecidamente estáveis em sua maioria, mostraram-se extremamente estáveis (apenas 12\% de perda de atividade) por um período de 6 meses, independentemente do procedimento de imobilização enzimática. Contudo, um efetivo controle de temperatura (armazenamento em geladeira) foi 
Tabela 5: Condições operacionais dos melhores sistemas de biossensores para detecção de fungicidas ditiocarbamatos

Tipo de sensor

Método de imobilização

Agente de imobilização

Enzima

Quantidade relativa de enzima

Substrato

Potencial de trabalho

Tempo de corrida cronoamperométrica

Valor de corrente, obtida durante a reação

enzima-substrato, após estabilização

Tempo de inibição com o pesticida ou a amostra de água

\section{Configuração do biossensor otimizado} PVC

Sensor serigrafado de três eletrodos: de referência $(\mathrm{Ag} / \mathrm{AgCl})$; auxiliar (grafite) e de trabalho (grafite, modificado com MBRS) 1) Reação cruzada, em meio contendo enzima de apoio (BSA, inerte)

2) Fotopolimerização

1) Glutaraldeído

2) PVA-SbQ

Aldeído desidrogenase (AldH)

0,8 U/eletrodo

Propionaldeído, $80 \mu \mathrm{M}$

$0,0 \mathrm{~V}$ versus $\mathrm{Ag} / \mathrm{AgCl}$

$10 \mathrm{~min}$

1) Fixação com glutaraldeído: $94 \pm 2 \mathrm{nA}$

2) Fixação da AldH em PVA-SbQ: $108 \pm 6$ nA

$10 \mathrm{~min}$

BSA = enzima soroalbumina bovina; MBRS = combinação de "Meldola Blue" com sal de Reinecke;

PVA-SbQ = álcool polivinílico contendo grupamentos estirilpiridínicos.

realizado durante esse período de estocagem, tendo sido evitada ainda a exposição à luz, para evitar oxidação da camada de $\mathrm{Ag} /$ $\mathrm{AgCl}$ (eletrodo de referência).

Com a configuração otimizada do biossensor (Tabela 5), poderá ser possível detectar, com precisão e sensibilidade adequadas, traços de DTC's diretamente em amostras ambientais (água, principalmente), em amostras fisiológicas (sangue, suor, urina) e, possivelmente em produtos agrícolas (frutos, verduras, etc.), desde que estes últimos possam ser liquefeitos ou que sejam pastosos, de modo a possibilitar a imersão do biossensor na matriz, e proceder ao ensaio de inibição conforme descrito anteriormente. A literatura registra outros inibidores da AldH, tais como dissulfiram e metabólitos ${ }^{41}$ e cinamida ${ }^{42}$ (compostos usados clinicamente para tratamento do alcoolismo); prunetina $^{43}$ (um derivado de isoflavonóides); óxido nítrico ${ }^{44}$; metilglioxal ${ }^{45}$ e ampal ${ }^{46}$ (metabólitos de alguns processos bioquímicos que ocorrem no fígado de mamíferos), entre outros. A possibilidade de resíduos de tais compostos serem encontrados em amostras ambientais ou nos alimentos é praticamente nula, o que torna improvável a interferência no sistema biossensor proposto.

A bioengenharia tem sido uma ferramenta importante no campo dos biossensores. Assim, enzimas têm sido modificadas geneticamente, com o objetivo de melhorar sua sensibilidade e seletividade frente a diferentes analitos ${ }^{47}$. Espera-se que, com as colaborações multidisciplinares, o surgimento de novas enzimas mutantes possa ser também útil na construção dos sensores à base de enzimas NAD-dependentes.

\section{CONCLUSÕES}

O estudo do comportamento da AldH livre, a partir da observação de parâmetros cinéticos $\mathrm{V}_{\max }$ e $\mathrm{K}_{\mathrm{m}}$, forneceu valores que indicam uma atividade enzimática adequada para construção de biossensores, a partir das soluções-estoque de AldH, boa afinidade com o substrato e elevada estabilidade. A máxima atividade foi definida a partir da otimização de parâmetros, como temperatura, $\mathrm{pH}$ do meio, concentração do cofator $\left(\mathrm{NAD}^{+}\right)$e tempo de reação.

A interpretação dos resultados obtidos eletroquimicamente permite concluir que o biossensor proposto pode ser uma ferramenta extremamente prática para a detecção indireta de fungicidas DTC's, baseada na inibição irreversível da enzima AldH por esses contaminantes. Para aplicação em análise de água, os LD's ainda se encontram dentro de uma faixa relativamente elevada; contudo, para aumentar a sensibilidade do método, podem ser empregados procedimentos de pré-concentração das amostras de água. Para análise direta de amostras vegetais, o biossensor mostra-se bastante sensível, já que os LD's estão abaixo dos LMR's estipulados pela legislação brasileira.

Esses resultados estimulam, ainda, a realização de estudos mais avançados, com a finalidade de reduzir a quantidade de enzima no eletrodo de trabalho, a partir da incorporação de elementos que possam potencializar sua atividade, ou mesmo na sua modificação genética; isso poderia aumentar a sensibilidade e, também, reduzir o custo final do biossensor. A possibilidade de emprego de outras técnicas de imobilização da AldH, como por ex. a fixação da enzima em uma matriz sol-gel, além do uso de diferentes mediadores eletroquímicos, poderão ser ainda estudados.

\section{AGRADECIMENTOS}

Ao suporte financeiro do Conselho Nacional de Desenvolvimento Científico e Tecnológico (CNPq). G. S. Nunes gostaria de expressar a sua gratidão à Prof ${ }^{a}$. Dra ${ }^{\text {a }}$ T. C. Santos (DETQI/UFMA), pelo importante apoio ao estudante de mestrado R. Lima, durante a sua ausência no ano de 2004.

\section{REFERÊNCIAS}

1. IAEAC - International Association of Environmental Analytical Chemistry; Sample Handling of Pesticides in Water, Active: Barcelona, 1994, p. 8-9.

2. IARC - International Agency for Research on Cancer; Occupational exposures in insecticide application, and some pesticides. Monographs on the evaluation of carcinogenic risk of chemicals to humans, Lyon: IARC, 1991, vol. 53.

3. IARC - International Agency for Research on Cancer; Genetic and related effects: an updating of selected IARC monographs from volumes 1 to 42 ., Lyon: IARC, 1987, vol. 53.

4. Cereser, C.; Boget, S.; Parvaz, P.; Revol, A.; Toxicology 2001, 163, 153.

5. Soloneski, S.; González, M.; Piaggio, E.; Reigosa, M. A.; Larramendy, M. L.; Mut. Res. 2002, 514, 201.

6. Teramoto, S.; Saito, R.; Shirasu, Y.; Teratology 1980, 21, 71.

7. Stocker, T. E.; Goldman, J. M.; Cooper, R. L. Reprod. Toxicol. 1993, 7, 211.

8. Zhou, Y.; Shie, F.-S.; Piccardo, P.; Montine, T. J.; Zhang, J.; Neuroscience 2004, 128, 281.

9. Vermeulen, L. A.; Reinecke, A. J.; Reinecke, S. A.; Ecotoxicol. Environ. Saf. 2001, 48, 183. 
10. OMS - Organização Mundial da Saúde; OPAS - Organização PanAmericana da Saúde; Manual de Vigilância da Saúde de Populações Expostas a Agrotóxicos, OPAS/OMS: Brasília, 1996, p. 32.

11. Tomlin, C., ed.; The Manual Pesticide - Incorporating The Agrochemicals Handbook, $10^{\text {th }}$ ed., Crop Protection Publications, BCPC:Cambridge, UK, 1995.

12. Barceló, D.; Hennion, M.-C. Em Techniques and Instrumentation in Analytical Chemistry; Barceló, D.; Hennion, M. C., eds.; Elsevier Science: Amsterdam, 1997, vol. 19.

13. Abalos, M.; Bayona, J. M.; Quevauviller P.; Appl. Organomet. Chem., 1998, 12,541 .

14. Schubert, P.; Fernandez-Escobar, I.; Rosenberg, E.; Bayona, J. M.; J. Chromatogr., A 1998, 810, 245.

15. Nunes, G. S.; Analytica 2004, 10, 50.

16. Horwitz, W., ed.; Official Methods of Analysis, $11^{\text {th }}$ ed., AOAC: Washington, 1970, p. 118-123.

17. Caldas, E. D.; Miranda, M. C. C.; Conceição, M. H.; Souza, L. C. K. R.; Food Chem. Toxicol. 2004, 42, 1877.

18. Lartiges, S. B.; Garfigues, P.; Analusis 1995, 23, 418.

19. Woodrow, J. E.; Seiber, J. N.; Fitzell, D.; J. Agric. Food Chem. 1995, 43,1524 .

20. Jongen, M. J. M.; Ravensberg, J. C.; Engel, R.; Leenheers, L. H.; J. Chromatogr. Sci. 1991, 29, 292.

21. Gustafsson, K. H.; Thompson, R. A.; J. Agric. Food Chem. 1981, 29, 729.

22. Sharma, V. K.; Aulakh, J. S.; Malik, A. K.; Talanta 2005, 65, 375.

23. Kubo, H.; Tsuda, Y.; Yoshimura, Y.; Homma, H.; Nakazawa, H.; Anal. Chim. Acta 2003, 494, 49 .

24. Hernández-Olmos, L.; Yánez-Sedeño, P.; Pingarrón, J. M.; Electrochim. Acta 2000, 46, 289.

25. Noguer, T.; Marty, J.-L.; Anal. Chim. Acta 1997, 347, 63.

26. Noguer, T.; Balasoiu, A. M.; Avramescu, A.; Marty, J.-L.; Anal. Chim. Acta 2001, 34, 513.

27. Vasilescu, A.; Noguer, T.; Andreescu, S.; Calas-Blanchard, C.; Bala, C.; Marty, J.-L.; Talanta 2003, 59, 751.

28. Calas-Blanchard, C.; Noguer, T.; Comtat, M.; Mauran, S.; Marty, J.-L.; Anal. Chim. Acta 2003, 484, 25.

29. Prieto-Simón, B.; Fàbregas, E.; Biosens. Bioelectron. 2004, 19, 1131.
30. Andreescu, S.; Noguer, T.; Magearu, V.; Marty, J.-L.; Talanta 2002, 57, 169.

31. Nunes, G. S.; Montesinos, T.; Marques, P. B. O.; Fournier, D.; Marty, J.-L.; Anal. Chim. Acta 2001, 434, 1.

32. Vasilescu, A.; Andreescu, S.; Bala, C.; Litescu, S. C.; Noguer, T.; Marty, J.L.; Biosens. Bioelectron. 2003, 18, 781.

33. Murray, R. K.; Granner, D. K.; Mayes, P. A.; Rodwell, V. W.; Harper's Biochemistry - A Lange Medical Book, $25^{\text {th }}$ ed., McGraw-Hill: New York, 2000, p. 86-101.

34. Michaelis, L.; Menten, M.; Biochemistry 1913, 49, 333.

35. Oishi, H.; Ebina, M.; J. Plant Physiol. 2005, 162, 1077.

36. Avramescu, A.; Noguer, T.; Avramescu, M.; Marty, J.-L.; Anal. Chim. Acta 2002, 458, 203

37. Avramescu, A.; Noguer, T.; Magearu, V.; Marty, J.-L.; Anal. Chim. Acta 2001, 433, 81 .

38. Nunes, G. S.; Jeanty, G.; Marty, J.-L.; Anal. Chim. Acta 2004, 523, 107.

39. ILSI - International Life Sciences Institute of Brazil; Monografias de Uso Agropecuário e Domissanitário, conforme Portarias e Resoluções do Ministério da Saúde - Agência Nacional de Vigilância Sanitária, ILSI: São Paulo, 2001

40. MMA - Ministério do Meio Ambiente; CONAMA - Conselho Nacional do Meio Ambiente; Resolução CONAMA no 357, de 17 de março de 2005, p. $1-23$

41. Velasco-García, R.; Chacón-Aguilar, V. M.; Hervert-Hernández, D.; MuñozClares, R. A.; Chem.-Biol. Interact. 2003, 143, 149.

42. Kinoshita, H.; Harbuz, M. S.; Jessop, D. S.; Finn, D. P.; Ameno, S.; Ameno, K.; Kubota, T.; Ijiri, I.; Forensic Sc. Int. 2000, 113, 397.

43. Sheikh, S.; Weiner, H.; Biochem. Pharmacol. 1997, 53, 471.

44. DeMaster, E. G.; Redfern, B.; Quast, B. J.; Dahlseid, T.; Nagasawa, H. T.; Alcohol 1997, 14, 181.

45. Izaguirre, G.; Kikonyogo, A.; Pietrusko, R.; Comp. Biochem. Physiol. Part B: Biochem. Mol. Biol. 1998, 119, 747.

46. Quash, G.; Fournet, G.; Chantepie, J.; Gore, J.; Ardiet, C.; Ardail, D.; Michal, Y.; Reichert, U.; Biochem. Pharmacol. 2002, 64, 1279.

47. Badea, M.; Romanca, M.; Draghici, C.; Marty, J.-L.; Marques, C. V. V. C. O.; Mendes, D. R.; Nunes, G. S.; J. Braz. Chem. Soc. 2006, 17, 807. 